\title{
Participatory Mapping Approaches Aided by GIS Technology towards Sustainable Land Use Planning in Namibia
}

\author{
Lisho C. Mundia \\ Department of Geo-Spatial Sciences and Technology, Namibia University of Science and Technology, Namibia
}

Copyright $(2016$ by authors, all rights reserved. Authors agree that this article remains permanently open access under the terms of the Creative Commons Attribution License 4.0 International License

\begin{abstract}
The empirical findings presented in this paper are for the participatory approaches in sustainable land use planning. The value of the Strengths, Weaknesses, Opportunities and Threats (SWOT), sketch and photo-mapping approaches aided by Geographical Information System (GIS) technology is emphasised. Various participants in Hardap region and experts associated with the Land Use Planning (LUP) development in that region provided their insightful knowledges, experiences and opinions on the value of participatory approaches aided by GIS technology in LUP. Combinations of research approaches were applied; these are literature review, the SWOT, sketch and photo mapping. Both positive and negative impacts of the approaches in evaluating the outcomes of the participatory mapping aided by GIS technology were gathered and the results were verified. The research established that the importance, the strengths and opportunities of participatory approaches in LUP are used in Namibia. There is however still a lack of knowledge on participatory methods to support land management programmes in Namibia. Key recommendations include awareness programme and intense studies on the potential value of participatory methods in LUP.
\end{abstract}

Keywords SWOT, Land Use Planning, GIS, Participatory Approaches, Sketch Mapping, Photo-mapping, Hardap Region, Namibia

\section{Introduction}

In this study, it was important to gather existing experiences of the participants and the acquisition of knowledge about how land should be used. This was done by using a participatory approach for data collection. Two methods of participatory mapping ${ }^{1}$ were applied in this

1 Participatory mapping is a map-making process that attempts to make visible the association between land and local communities by using the commonly understood and recognized language of cartography study namely sketch mapping ${ }^{2}$ and photo-mapping ${ }^{3}$. The steps, outcomes and purpose of these two methods are different. Clifford and Valentine [1] believe that "utilizing a variety of data collection methods and a division of labor that consciously builds upon the strengths of each member of the team is one way to assure widespread participation." A SWOT analysis was conducted as a means of organizing some of the issues and factors promoting and acting against participatory methods (Carver [3]).

\section{The Study Area (Hardap Region)}

After Namibia's independence in 1990, the Hardap region was divided into six political constituencies: Gibeon, Mariental Rural, Mariental Urban, Rehoboth Rural, Rehoboth Urban East and Rehoboth Urban West (Government of Namibia [2]). In August 2013, the Hardap region was re-demarcated with two extra constituencies (Aranos and Daweb) by the President after the fourth Delimitation Commission's recommendation to bring about better service delivery to the community of the Hardap region. However, this study was done in the six original Hardap political constituencies. This is because the practical components (SWOT, sketch mapping and photo mapping) of the study were already done before the re-demarcation was implemented and there is still lack of data in the two new constituencies.

In terms of land, private farmers on a freehold basis own approximately $75 \%$ of the surface area of the Hardap region.

(International Fund for Agricultural Development [4])

2 Sketch mapping is a slightly more elaborate method. A map is drawn from observation or memory. It does not rely on exact measurements, such as having a consistent scale, or georeferencing. It usually involves drawing symbols on large pieces of paper to represent features in the landscape (Corbett et al. [5]).

3 Photo-mapping is the photo-mapping approach is usually carried out on the printouts of geometrically corrected aerial photographs (orthophotos) placed in map coordinate systems (Rambaldi et al.,[6]). Orthophoto maps are occasionally a source of accurate remotely sensed data that may be used for large-scale community mapping. 
The second largest landowner is the government that owns the extreme western part that constitutes approximately $15 \%$ of the area and is designated as part of the Namib-Naukluft Park. The central-southern part of the region is designated as communal farmland representing about $10 \%$ of the area over which traditional authorities and small-scale farmers hold control (Government of Namibia, [2]).

Mendelsohn et al., [7] stressed that "other small parcels of land, scatted throughout the region, are owned by government, including about ten resettlement farms, two parcels dedicated to government agriculture and one additional protected area surrounding the Hardap Dam. Ten (10) designated local authorities are situated in different areas within Hardap Region with the largest being Rehoboth in the far north of the region and including the regional capital, Mariental located further in the south.”

The study area is located in the south of Namibia, as seen on Figure 1. The Hardap region measures about 109000 $\mathrm{km}^{2}$ and the region has a population of approximately 79 000 people (Namibia Statistics Agency [8]). The region was chosen mainly due to a presence of a combination of issues that may easily lead to land disputes. These issues include, environmental issues, competitive industries who use the land for mining, agriculture and nature conservation, and an uneven distribution of infrastructure, such as boreholes, wind pumps and water canals. Flooding of the area has occurred when the sluice gates of Hardap Dam had to be opened to control dam water level. It is mainly the town of Mariental that has been affected by such flooding.

The participatory approaches aided by GIS for sustainable LUP was carried out in six different land portions as per constituencies of the Hardap region. The land portions where participatory mapping took place vary in land uses. Participatory mapping exercises were carried out at selected sites in each of the six constituencies of the Hardap region. These included rural, peri-urban and urban sites.

The use of the word 'Hardap' as the name of the region reflects the prominent role of the Hardap Dam in the agro-economic and tourism sectors of this region. The two major towns of the region are Rehoboth and Mariental.

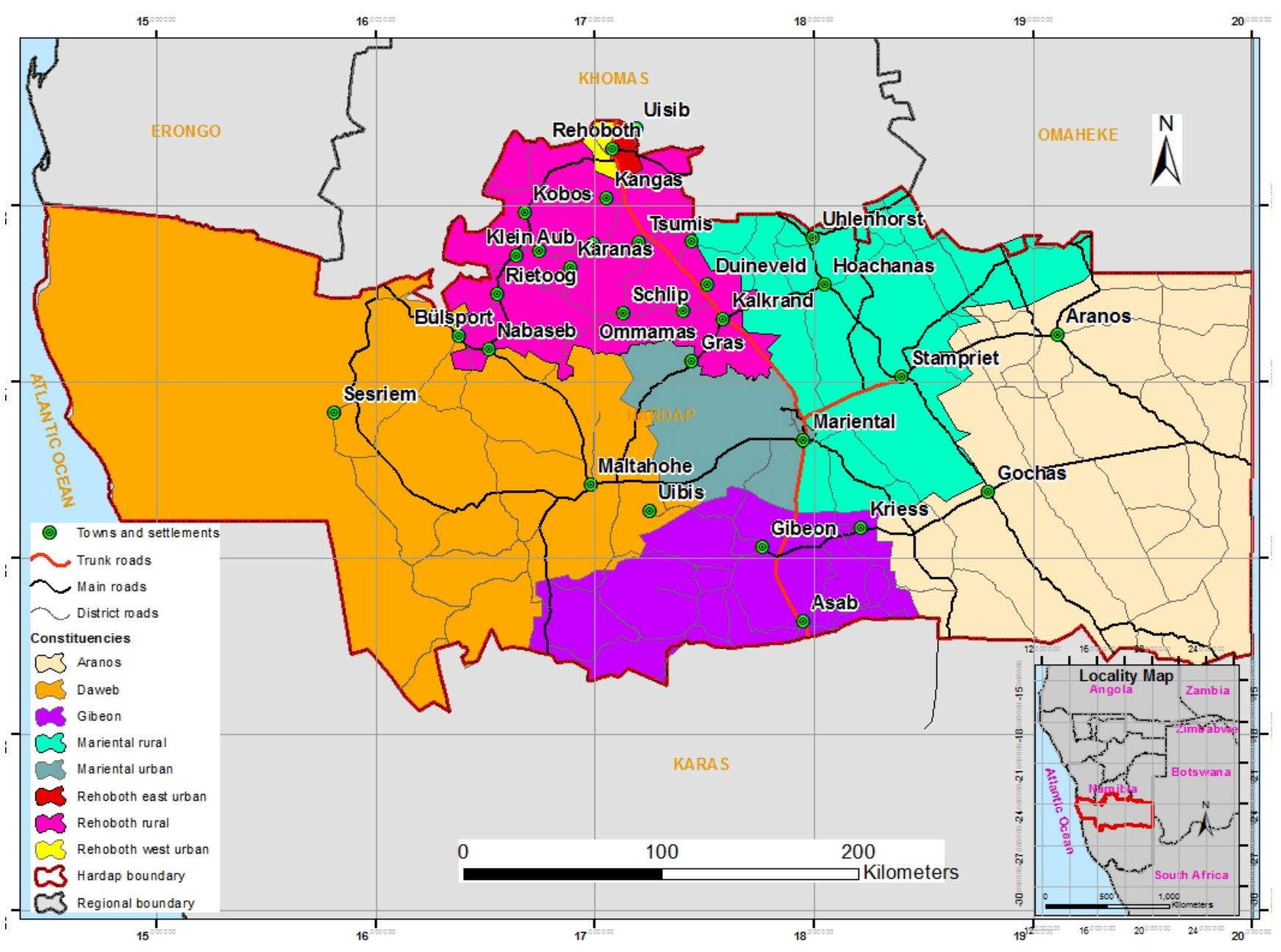

Figure 1. Study area 


\section{The Methodology Perspective}

A SWOT analysis was conducted in the local communities and experts. Some experts were selected from the fields of LUP, geography and GIS within the Hardap region and others from the central government in the Khomas region who are familiar with the Hardap region's development.

The SWOT method was used to evaluate the outcomes of participatory approaches aided by GIS for sustainable land use management in Namibia. The SWOT analysis was realized by gathering knowledge through consultation meetings with local and regional communities from the Hardap region and different experts in Namibia with relevant experience of LUP and GIS. The SWOT approach was used to establish the interactions between local people and experts. Assessments of how SWOT analysis method contributed to the research process were discussed with the participants accordingly.

The SWOT analysis helps identifying a strategy and related actions to build on positive factors and to mitigate the potential impact of or overcome negative factors. The procedures used to conduct a SWOT analysis in this study were as follow:

- Invite participants (same participants as for participatory mapping);

- $\quad$ hand out marker pens to all members;

- display sheets of paper, each displaying a SWOT grid (for example, strengths or weakness) respectively;

- clarify the specific item to be assessed and define terms, for example, strengths, weaknesses, opportunities and threats, in the context of the internal and external environments of the community;

- verify that everybody has a clear understanding of the objective of the SWOT analysis;

- ask the participants to think of all the strengths, weaknesses, opportunities and threats;

- gather the ideas and opinions, write them on the SWOT grid or paper;

- $\quad$ ask one participant to read the grids aloud one at a time and encourage discussion on each issue;

- $\quad$ ask if the participants have any more points to add after they have heard everyone else's point of view;

- facilitate the analysis of results;

- give the participants enough time to think about their answers; and

- discuss results with the participants and solicit agreement.

Participatory mapping approaches took place in different units of land within the six constituencies of the Hardap region. Participatory sketch mapping and photo-mapping were used with local communities' participation in their respective areas in order to respond to the research objective of producing participatory land use maps from different units of land within the six constituencies of the Hardap region by local communities. Participatory sketch mapping and photo-mapping were used to gather spatial knowledge from the participants by producing stand-alone maps. Different color pens we used to distinguish between features to represent real world features, such as points, lines and polygons. With regard to photo-mappings, this was performed on prints of geometrically corrected satellite images, aerial photographs and orthophotos.

To make the map, the participants were invited to sketch their mental maps and perceptions on the ground or on paper. The participants visualize space-related features. These may vary depending on the characteristics of the participants, for example, whether they are men or women, youth or elderly. A legend is then created and is agreed-upon by the participants to represent various themes such as land cover or land use and infrastructure and features such as roads, river, schools and houses.

\section{Context on Participatory Approaches in Spatial Planning}

Lai and Rivera [9] stated that "the SWOT (Strengths, Weaknesses, Opportunities and Threats) analysis is an environmental scanning tool used to facilitate discussion and identify key criteria in situation analysis and problem solving. It is most often used in marketing or management strategy development. SWOT is a flexible tool that can be applied to situations and problems in a wide range of disciplines." Gupta [10] in the study titled 'SWOT analysis of geographic information: The case of India', used SWOT analysis. The tool was used to evaluate the geographical information of India SWOT analysis helps in identifying and evaluating strengths, weaknesses, opportunities, and threats that LUP organizations and project implementers face in given circumstances and to develop options to deal with external threats and exploit opportunities by matching external possibilities with internal capabilities.

According to Carver [3], "the industry standard strategic response to any SWOT analysis is simply to build on your strengths, address your weaknesses, exploit the opportunities and neutralise any threats. The same can be said of participatory mapping and GIS."

SWOT analysis is a tool commonly used as part of strategic planning processes. It is a way to structure community members' ideas, thoughts and beliefs related to a particular decision such as selection of a mapping method or a combination of mapping methods to meet one or more goals. Gupta [10] concluded in the study that "geographical information is today being extensively used in decision-making processes because it has become a fundamental element to provide better understanding about one's surroundings." Strengths and weaknesses focus on the internal factors (within the community), while opportunities and threats reflect the influences of the external environment affecting the organization, community or 
activity. These may include cultural, political, economic, environmental, technical and other dimensions.

According to Müller and Wode [11] consultants to collect and manipulate data used in the preparation of land use maps often use conventional approaches such as GIS and remote sensing. The said consultants sometimes lack in-depth knowledge of the local resources locations, which, depending on the mapping approaches may lead to inaccurate delineation, and misinterpretation of land use classes. Müller and Wode [11] emphasized that "the objective of participatory mapping is to enable villagers to carry out the interpretation of aspects of their land resources that are of significant importance to the community, in this process villagers delineate their land use on transparencies laid over an ortho-photograph." Involving local stakeholders with their extensive field experiences is expected to improve the accuracy and precision of obtained data.

Participatory mapping has two decades of applications in participatory spatial planning, whether manifested as rural-located 'community-based natural resources' or as 'participatory neighborhood planning' in urban settings. Participatory mapping has been commonly used in claiming land, management of customary land and resources, mapping social and environmental inequalities and strengthening community awareness and cultural identity (McCall and Minang [12]).

\section{The Results Perspectives}

Participatory approaches have emerged as a contemporary spatial planning paradigm at national, regional and local levels (Corbett et al., [5]). LUP frameworks require effective stakeholder participation especially in developing countries like Namibia which are overwhelmed with random land developments and lack of institutional arrangements for enforcing local laws. Participatory mapping has been identified as one of the methods by which LUP can be used to achieve development goals such as creating a healthy, convenient, economically functional and pleasing living environment (International Fund for Agricultural Development [4]). It is a powerful tool that increases stakeholder involvement and provides a means for participants to express their ideas in an easily understandable visual format.

In general, participatory approaches can help provide:

- a way to engage stakeholders near and far;

- objective local information on resources;

- traditional knowledge and practices of the community;

- information on how communities perceive, value, and use resources;

- a focal point for discussions on land use issues;

- a valuable tool to support decision-making; and

- graphical and easily understandable communication tools.

SWOT analysis was conducted as a means of organizing some of the issues and factors promoting and acting against participatory methods (Carver [3]). A summary of the results of the SWOT analysis are provided in Table 1. The Table shows views and opinions of both local communities and experts from government ministries and other organizations.

Table 1. A SWOT analysis focusing on the results of participatory mapping approaches aided by GIS in LUP in Namibia

\begin{tabular}{|c|c|}
\hline \multicolumn{2}{|l|}{ INTERNAL FACTORS } \\
\hline Strengths & Weaknesses \\
\hline $\begin{array}{l}\text { Participatory mapping approaches and GIS are recognised as the best practice tools for involving local } \\
\text { communities' contributions to participatory LUP. } \\
\text { Participatory mapping approaches can be understood by local communities involved. } \\
\text { Government recognises local communities' opinions and viewpoints in LUP country-wide. } \\
\text { Participatory mapping approaches provide the platform to gather good knowledge of local resources from } \\
\text { the local communities. } \\
\text { There is an acceptable theoretical knowledge of participatory mapping by local communities and experts in } \\
\text { relevant offices. } \\
\text { Participatory mapping approaches have been accepted in most countries as a tool for collection of data on the } \\
\text { participant's experiences and their surroundings for LUP. } \\
\text { Participatory mapping approaches promote community awareness, institutional strengthening and } \\
\text { empowerment of local inhabitants. } \\
\text { Participatory mapping approaches can be used as a tool in managing and reducing conflicts between } \\
\text { community members. } \\
\text { GIS helps manage, integrate, identify, locate, and analyse natural resources in Hardap region. } \\
\text { GIS provides the integration of all the data gathered from participatory mapping and other sources. } \\
\text { GIS allows efficient data manipulation, retrieval and presentation of spatial data. }\end{array}$ & $\begin{array}{l}\text { No LUP policies exist to implement } \\
\text { the integration of participatory } \\
\text { mapping aided by GIS into the } \\
\text { integrated LUP. } \\
\text { The decentralisation of LUP } \\
\text { processes in Namibia is not fully } \\
\text { deployed to regional and local levels } \\
\text { as it is only known at national level. } \\
\text { Participatory mapping approaches } \\
\text { are not widely recognised at } \\
\text { grassroots level for LUP in the } \\
\text { Hardap region. }\end{array}$ \\
\hline \multicolumn{2}{|l|}{ EXTERNAL FACTORS } \\
\hline Opportunities & Threats \\
\hline $\begin{array}{l}\text { The Spatial Data Infrastructure (SDI) policy was approved by parliament could open doors for enormous } \\
\text { reorganisation of spatial data management. } \\
\text { Participatory mapping approaches promote ownership of resources, information sharing and consultation on } \\
\text { land matters. } \\
\text { Participatory mapping approaches promote sharing of natural resources such as rivers, forests, and many } \\
\text { others. } \\
\text { Participatory mapping approaches promote information awareness. } \\
\text { Participatory mapping approaches promote sharing of benefits such as infrastructure. } \\
\text { Participatory mapping approaches is been implemented as best practice for local knowledge gathering in } \\
\text { other countries such as Kenya and South Africa. }\end{array}$ & $\begin{array}{l}\text { Ignorance of some of the } \\
\text { office-bearers responsible for } \\
\text { planning and decision-making. } \\
\text { Serious time constraints involved in } \\
\text { participation processes. } \\
\text { Participation may be costly. }\end{array}$ \\
\hline
\end{tabular}


Sketch mapping was found to be difficult for first time users and a very time consuming approach. This was because of the amount of time required by participants to verify certain geographical features within their environment before they started sketching the maps. In addition, lack of basic mapping skills by some community members contributed, as the sketch maps sometimes turned out to be unclear. It was, however, found to be a useful participatory tool in collecting information about issues surrounding the communities and how they live.

Photo-mapping was based on delineation of features interpreted from aerial photographs. The participants selected this method as it proved to be easier than other forms of mapping, such as sketch mapping. The interpretation process involved delineating features which the participants could recognize, describe and explain. Interpreting an aerial photograph or a small part of an aerial photograph was less problematic for the users. The features, which were unclear on the map, could be verified on the ground. The mapped features were based on what could be observed on the aerial photographs. Different features on aerial photographs were described using different keys as legends. Those keys were then used to explain the symbols depicted on the map.

\section{Conclusions}

The major objective of research was to describe opinions and experiences about participatory mapping approaches aided by GIS for sustainable land use management in Namibia obtained by means of a SWOT analysis. The SWOT analysis was used to evaluate the outcomes of participatory mapping aided by GIS for sustainable LUP in Namibia. The SWOT gathered opinions, perceptions and views from local communities and experts in the Hardap region.

The research question dealing with the role of participatory mapping approaches aided by GIS in LUP and management in Namibia was validated. This is because the study result shows that the importance, the strengths and opportunities of participatory approaches in integrated LUP exists in Namibia. However, there is still a lack of expertise about participatory methods, specifically participatory mapping in order to support land management programmes in Namibia.

\section{Acknowledgements}

I am very grateful to the Namibia University of Science and Technology for the sabbatical leave. It allowed me sufficient time to complete this paper.

\section{REFERENCES}

[1] Clifford, N, J., and Valentine, G. Key methods in geography. London: SAGE Publications, 2003.

[2] Government of Namibia. Regional poverty profile: based on village-level participatory poverty assessment in Hardap region. National Planning Commission, 2006.

[3] Carver, S. Participation and geographical information. A position paper, ESF-NSF workshop on access to geographic information and participatory approaches using geographic information, Online available from www.shef.ac.uk/Bscgisa/ spoleto/workshop.htm

[4] International Fund for Agricultural Development. Good practices in participatory mapping: A review prepared for the International Fund for Agricultural Development, Online available from http://www.ifad.org/pub/map/PM_web.pdf

[5] Corbett, D., Rambaldi, G., Kyem, P. A. K., Weiner, D., Olson, R., Muchemi, J., McCall, M. and Chambers, R. Overview: mapping for change - the emergence of a new practice, Online available fromhttp://www.iapad.org/publications/ppg is/ch01_overview_pp13-19.pdf

[6] Rambaldi, G., Kyem, P. A. K., McCall, M. and Weiner, D. Participatory Spatial information management and communication in developing countries, Online available from http://www.ejisdc.org/ojs2/index.php/ejisdc/article/vie wFile/237/158

[7] Mendelsohn, J., Jarvis, A., Roberts, C. and Robertson, T. Atlas of Namibia: a portrait of the land and its people. Ministry of Environment and Tourism, Windhoek, 2002.

[8] Namibia Statistics Agency. Namibia 2011 Population and housing census basic report. Namibia Statistics Agency, Windhoek, 2013.

[9] Lai, C.A. and Rivera, J.C. Case teaching notes for "a lake runs through it . . .or is it a river? or something else?", Online available from http://www.sciencecases.org/tempe_lake/tem pe_lake_notes.pdf

[10] Gupta, R. SWOT analysis of geographic information: The case of India, Online available fromhttp://www.ias.ac.in/currsci/a ug252000/ravigupta.pdf

[11] Müller, D. and Wode, B. Manual on participatory village mapping using photomaps. Social Forestry Development Project (SFDP) Song Da. Son La, 2003.

[12] McCall, M. K and Minang, P.A. 2005. Assessing participatory GIS for community-based natural resource management: claiming community forests in Cameroon. The Geographical Journal. Vol. 171 (4) 340-356. 